\title{
The Influence of Product Market Externality on Dynamic Decisions of Monopoly
}

\author{
Yan Wang ${ }^{1,2 *}$, Deqing Tan ${ }^{1}$ \\ ${ }^{1}$ School of Economics and Management, Southwest Jiaotong University, Chengdu, China \\ ${ }^{2}$ Department of Economics and Management, Sichuan College of Architectural Technology, Deyang, China \\ Email: *wyswjtu@126.com
}

How to cite this paper: Wang, Y. and Tan, D.Q. (2017) The Influence of Product Market Externality on Dynamic Decisions of Monopoly. Modern Economy, 8, 806-815. https://doi.org/10.4236/me.2017.86056

Received: April 28, 2017

Accepted: June 10, 2017

Published: June 13, 2017

Copyright (C) 2017 by authors and Scientific Research Publishing Inc. This work is licensed under the Creative Commons Attribution International License (CC BY 4.0).

http://creativecommons.org/licenses/by/4.0/

\begin{abstract}
The externality of the goods in the market affects the diffusion process of the product, and also affects the price strategy and advertising strategy that manufacturer makes in the diffusion process of the product. Positive externalitiy can accelerate the speed of the product diffusion, increase product sales, and save the cost of advertising in order to increase enterprise's profit; Strong negative externality reduces product sales, increases enterprise's advertising costs and makes losses. Under the market of the monopoly structure, considering the effect of products' externality, product price and advertising investment on the product's demand, builds the dynamic decision model of the product and uses the control theory to get the manufacturer's optimal price strategy and optimal controlling strategy of the advertisement expenditure, and relatively analysis the changing trend of optimal controlling strategy, the product's diffusion process and manufacturer's profit on the different condition of positive and negative externality, and obtains some conclusions which are provides theory support for the decision enterprise makes.
\end{abstract}

\section{Keywords}

Monopolisitic Manufacturer, Market Externality, Product Price, Advertising Expenditure, Optimal Controlling

\section{Introduction}

Many scholars have concentrated on studying product market externality. With the rapid development of information technology, it is also changing that the operational management models for emerging market. Especially the emergence of the Internet economy and electronic commerce, the importance of product externality for manufacturers is also becoming more and more prominent. In the context, the Internet is widely used in enterprise operation and management, 
so consumers no longer rely solely on the market or media (such as product price, advertising, etc.) information to make a purchase decision. They are more willing to obtain product information through communicating with each other on the Internet or by other means. And so, the reviews of consumers who have already used product posted are particularly important. For example, millet community forum is the base of consumers where they can exchange mobile phone using skills experience and participate in interactive activities. So it is an important way for potential consumers to get the product information before making a purchase decisions. And millet phone does not have the high amount of advertising and marketing promotion to attract consumers. Online shopping has become a popular consumption model, and it is the main way to get information on product using by visiting product evaluation information on the Internet. They make purchase decisions based on the buyer's comments on the product. Of course, in the early stage of the new product into the market, manufacturers need to advertise the product so that consumers can know it. Once the product has a certain number of consumers in the market, buyers who are using the product will have a certain impact on the sales. The impact is defined as product externality in this paper. Positive impact can accelerate the proliferation of products and increase sales, but negative impact will hinder the spread of products and reduce sales. In the case of the existence of external products, this article investigates pricing policy and advertising investment policy, and further how to change the company's sales. And this paper studies the influence of the products' externality on the firm's price and advertisement strategy from the dynamic point of view, which expands the perspective of the study of externalities, and also provides suggestions for the enterprise operation decisions.

\section{Literature Review}

Recently, many scholars have been working on research the impact of product market externality on product diffusion, but mainly focusing on the following aspects. Bass model is the basic model to study the diffusion of product, and the factors that affect the product demand are divided into two categories: internal and external influences [1]. Kalish and Sen (1986) pointed out that price was the most key factor affecting the actual demand, and the Bass model ignored the impact of the price [2]. After that, Jain and Rao (1990) defined the actual aggregate demand as a function of price, but there was no explanation of how the price affected consumer choice behavior [3]. Then Xie and Sirbu (1995) established a dynamic model of product diffusion that included price and product externality, but only analyzed the impact of positive externality on firm decision [4]. At the same time, some studies only considered the impact of negative externality on product demand and firm decisions, such as (Saito Richard 1994, Goolsbee Austan et al. 2000, Laussel Didier et al. 2004, Berger Jonah et al. 2010, etc) [5] [6] [7] [8]. Pan Xiaojun et al. (2006) considered that the externality of the product had an important influence on consumer expectations, and the two stage dynamic model was established. Under the condition of external externali- 
ty to analyzed the pricing strategy of monopoly in the case of homogeneous and heterogeneous products in different stages under the condition of external externality [9]. Puneet Manchanda et al. [10] pointed out that the two factors that affecting consumer buying decisions were the exchange of consumer's individual and marketing information, analyzed the influence of market strategy (price, advertisement) and social contagion (consumer's oral communication effect) on consumer purchasing decision. They found that the market strategy played a major role in product diffusion in the early stage of product entering into market, but the effect of social infection was greater than that of market strategy after entering stable period [10]. The phenomenon of mutual learning among consumers was a form of expression of the externality of the product. Jing Bing [11] established the two stage dynamic model of durable goods, and researched the effects of social learning on product pricing and purchasing decisions. In the era of network economy, the influence of oral communication and social learning on product diffusion is particularly important. Nielsen [12] pointed out that $70 \%$ of online shoppers had more confidence in the information about anonymous people than the trust of advertising information. Nielsen [13] found that $46 \%$ of Internet users relied on social media information to make purchase decisions. Gopinath Shyam et al. [14] used empirical research methods to analyze the relative importance of consumer online reviews and advertising on product diffusion. David [15] examines the equilibrium relationship between product quality and word-of-mouth (WOM) communication. Fossen and Schweidel [16] used data to analyze the relationship between television advertising and online word-of-mouth (WOM). The differential game theory is a primary method to study the impact of advertising investment, with establishing the differential model of advertising reputation to realize the interest coordination among members, such as [17] [18] [19] [20].

In summary, the effect of externality on product diffusion is a dynamic and gradual process, and it also affects firms' price decision in the process of product diffusion. But the existing literature mainly discussed the topic from the static point. So the dynamic model is established to analyze dynamic decision problem in the case of product externality. In addition, combining with the diffusion theory, this paper discusses the influence of the externality of the products on the dynamic pricing, advertising investment decisions and sales of the monopoly in the process of product diffusion.

\section{Model Analysis}

\subsection{Demand Model}

In fact, the products that have been sold take a certain impact on the potential demand in the market. Such as, consumers who have used the product communicate messages with potential buyers about quality and price of products via network platform or verbally. The better evaluations have a positive impact on product sale, otherwise it will hinder the product sales, and that is, the product has a negative market externality. Suppose the monopoly produces a product, 
and at time $t$ the potential demand is $a$; sales price is $p(t) ; D(t)$ is cumulative sales of products. While the level of advertising investment is $m(t)$, and the function of advertising input cost is $k \cdot m^{2}(t) / 2$. Hypothetical at time $t$ the sales of products is $D^{\prime}(t)$, relationship between the price, advertising input level and cumulative sales must satisfy the following Formula (1):

$$
D^{\prime}(t)=a-b \cdot p(t)+r \cdot m(t)+\lambda \cdot D(t)
$$

And the influencing factor of price to sales is $b>0$; the influencing factor of the advertising investment level to sales is $r>0, \lambda$ is the influencing factor of cumulative sales to sales, $\lambda$ also said the external effect of the been sold products. When $\lambda>0$, there is the positive market externality and when $\lambda<0$, there is the negative market externality.

Without affecting the conclusion and loss of generality, the fixed cost of products and marginal cost is zero. In this paper, we study the dynamic decision problem of monopoly manufacturer in the time frame of $[0, T]$. And $D(T)=a$ means that all consumers will have purchased the product at $T$ time. So when the product price is $p(t)$, advertising investment level is $m(t)$ and the discount factor is $\rho$, the profit function of monopoly firms in $[0, T]$ period can be expressed as:

$$
\begin{gathered}
\max _{p(t), m(t)} \pi=\int_{0}^{T} \mathrm{e}^{-\rho \cdot t} \cdot\left[p(t) \cdot D^{\prime}(t)-\frac{1}{2} k \cdot m^{2}(t)\right] \mathrm{d} t \\
\text { s.t } \quad D^{\prime}(t)=a-b \cdot p(t)+r \cdot m(t)+\lambda \cdot D(t) \\
\quad D(0)=d_{1}, D(T)=a .
\end{gathered}
$$

The optimal control theory will be used to solve the optimal price control strategy and the optimal advertising input level control strategy.

\subsection{Analysis of Price Strategy and Advertisement Strategy}

Due to the complexity of the model, this article refers to Nair and Narasimhan [2] solution method, solving the optimal solution by open loop control strategy. In order to obtain optimal price control strategy and optimal advertising input level control strategy, the Hamiltonian function of Formula (2) is:

$$
\begin{aligned}
H= & (a-b \cdot p(t)+r \cdot m(t)+\lambda \cdot D(t)) \cdot p(t)-\frac{1}{2} k \cdot m^{2}(t) \\
& +\mu \cdot(a-b \cdot p(t)+r \cdot m(t)+\lambda \cdot D(t)) .
\end{aligned}
$$

$\mu$ is a co state variable, and needs to meet the following conditions:

$$
\begin{gathered}
\frac{\partial H}{\partial p(t)=}(a-2 b \cdot p(t)+r \cdot m(t)+\lambda \cdot D(t))-\mu \cdot b=0 \\
\frac{\partial H}{\partial m(t)}=r \cdot p(t)-k \cdot m(t)+\mu \cdot r=0 \\
\frac{\partial H}{\partial \mu}=D^{\prime}(t)=a-2 b \cdot p(t)+r \cdot m(t)+\lambda \cdot D(t) \\
\dot{\mu}=\rho \cdot \mu-\frac{\partial H}{\partial D(t)}=\rho \cdot \mu-(\lambda \cdot p(t)+\lambda \cdot \mu) .
\end{gathered}
$$


Proposition 1 gives the optimal price control strategy and optimal advertising input level control strategy.

Proposition 1: When sold products have positive market externality $(\lambda>0$ and $\left.r^{2}<2 b k\right)$ or with negative externality $\left(\lambda<0\right.$ and $\left.r^{2}>2 b k\right)$, the optimal price control strategy and optimal advertising input level control strategy of monopoly firms are

$$
\begin{gathered}
p^{*}(t)=\frac{\left((A-2 \lambda f) r^{2}-(A-4 \lambda f) b k\right)}{2 b^{2} k} \cdot\left(d_{1}+\frac{a}{\lambda}\right) \cdot \mathrm{e}^{\frac{A t}{2}} \\
m^{*}(t)=\frac{A r}{2 b k} \cdot\left(d_{1}+\frac{a}{\lambda}\right) \cdot \mathrm{e}^{\frac{A t}{2}}
\end{gathered}
$$

Proof: Through the simultaneous solution (4) and (5), the optimal price and optimal advertising input level are:

$$
\begin{gathered}
p^{*}(t)=\frac{a k+\lambda k \cdot D(t)+\left(r^{2}-b k\right) \cdot \mu}{2 b k-r^{2}} ; \\
m^{*}(t)=\frac{a r+\lambda r \cdot D(t)+b r \cdot \mu}{2 b k-r^{2}} .
\end{gathered}
$$

By taking the optimal price $p^{*}(t)$ and the optimal advertising input level $m^{*}(t)$ into (6) and (7), we can obtain

$$
\begin{gathered}
D^{\prime}(t)=a f+\lambda f \cdot D(t)+b f \cdot \mu ; \\
\mu^{\prime}=(\rho-\lambda b q) \cdot \mu-\lambda a q-\lambda^{2} q \cdot D(t) .
\end{gathered}
$$

By solving differential of the Formula (10) on both sides, it can be obtained:

$$
D^{\prime \prime}(t)=\rho \cdot D^{\prime}(t)-\rho \lambda f \cdot D(t)-\rho a f .
$$

Without loss of generality, we as well set $\rho=1$, it is easy to know that there is a characteristic root for the positive in formula. In order to get the convergence of the differential equation, there must be a negative root, and then must meet the condition of $\lambda f<0$ i.e. $\left(\lambda>0\right.$ and $\left.r^{2}<2 b k\right)$ or $\left(\lambda<0\right.$ and $\left.r^{2}>2 b k\right)$. When the boundary condition is $D(0)=d_{1}$ and $D(T)=a$, solving integral of the Formula (12), it can be obtained:

$$
\begin{gathered}
D(t)=-\frac{a}{\lambda}+\left(d_{1}+\frac{a}{\lambda}\right) \cdot \mathrm{e}^{t \cdot(\sqrt{1-4 \lambda f}+1) / 2} . \\
\mu(t)=\frac{A-2 \lambda f}{2 b f} \cdot\left(d_{1}+\frac{a}{\lambda}\right) \cdot \mathrm{e}^{t \cdot(\sqrt{1-4 \lambda f}+1) / 2}
\end{gathered}
$$

According to the previous hypothesis $\lambda f<0$, so the condition $(\sqrt{1-4 \lambda f}+1>1)$ is true. Obviously when the parameters $\lambda$ and $d_{1}$ are positive, the demand is holding. In addition, because the product's immediate sales cannot be negative i.e. $\left(D^{\prime}(t)>0\right.$ and $\left.D(T)=a\right)$, so it must be meet $\lambda<-1$ meanwhile $d_{1}>-\frac{a}{\lambda}$. And the following analysis of the negative externality of the product are discussed under the conditions of $\lambda<-1$.

By taking the Formula (13) and Formula (14) into the Equations (8) and (9), the optimal price and optimal advertising input level can be followed as 


$$
\begin{gathered}
p^{*}(t)=\frac{(A-2 \lambda f) r^{2}-(A-4 \lambda f) b k}{2 b^{2} k} \cdot\left(d_{1}+\frac{a}{\lambda}\right) \cdot \mathrm{e}^{\frac{A t}{2}} ; \\
m^{*}(t)=\frac{A r}{2 b k} \cdot\left(d_{1}+\frac{a}{\lambda}\right) \cdot \mathrm{e}^{\frac{A t}{2}}
\end{gathered}
$$

and $A=\sqrt{1-4 \lambda f}+1$. Proof is finished.

Proposition 2: When sold products have positive market externality i.e. $\left(\lambda>0\right.$ and $\left.r^{2}<2 b k\right)$ and the external strength meets $\lambda>\sqrt{\frac{A\left(r^{2}-b k\right)}{2 b k d_{1}}}$, the optimal price $p^{*}(t)$ is higher with the increasing of externality; when market externality is negative i.e. $\left(\lambda<-1\right.$ and $\left.r^{2}<b k\right)$, the optimal price $p^{*}(t)$ is higher with the decreasing of negative externality (the absolute value of $\lambda$ decreases); under other conditions, the variation trend of the optimal price $p^{*}(t)$ is uncertain along with the change of external intensity.

Proof: Because $p^{*}(t)=\frac{(A-2 \lambda f) r^{2}-(A-4 \lambda f) b k}{2 b^{2} k} \cdot\left(d_{1}+\frac{a}{\lambda}\right) \cdot \mathrm{e}^{\frac{A t}{2}}$, therefore

$$
\begin{aligned}
\frac{\partial p^{*}(t)}{\partial \lambda}= & \frac{\partial A}{\partial \lambda} \cdot\left(\frac{r^{2}-b k}{2 b^{2} k}+\frac{A\left(r^{2}-b k\right) \cdot t}{4 b^{2} k}+\frac{\lambda \cdot t}{2 b}\right) \cdot\left(d_{1}+\frac{a}{\lambda}\right) \cdot \mathrm{e}^{\frac{A t}{2}} \\
& +\left(\frac{d_{1}}{b}-\frac{A\left(r^{2}-b k\right)}{2 b^{2} k \cdot \lambda^{2}}\right) \cdot \mathrm{e}^{\frac{A t}{2}} \cdot
\end{aligned}
$$

Because $\frac{\partial A}{\partial \lambda}=\frac{-2 f}{\sqrt{1-4 \lambda f}}$ and the previous assumptions about $\lambda$ and $f$, so if $\lambda>0, \frac{\partial A}{\partial \lambda}>0$; there is $\lambda<-1$ and $\frac{\partial A}{\partial \lambda}<0$. Through the analyzing of Formula (17), it is found that $\frac{\partial p^{*}(t)}{\partial \lambda}>0$ is established when $\lambda>0$ and $r^{2}>2 b k$ meantime the external strength of $\lambda>\sqrt{\frac{A\left(r^{2}-b k\right)}{2 b k d_{1}}}$. When $\lambda<-1$ and $r^{2}<b k, \frac{\partial p^{*}(t)}{\partial \lambda}>0$ is clearly established. Proposition 2 was proved.

Proposition 3: When sold products have positive market externality i.e. $\lambda>0$ and $r^{2}>2 b k$ and the external strength meets

$$
0<\lambda<\frac{\sqrt{\left(a \cdot \frac{\partial A}{\partial \lambda}\right)^{2}+4 A a \cdot \frac{\partial A}{\partial \lambda} \cdot\left(d_{1}+\frac{A t}{2}\right)}-a \cdot \frac{\partial A}{\partial \lambda}}{\frac{\partial A}{\partial \lambda} \cdot\left(2 d_{1}+A t\right)}
$$

the optimal advertising input level $m^{*}(t)$ is higher with the increasing of external intensity; when the external strength meets

$$
\lambda>\frac{\sqrt{\left(a \cdot \frac{\partial A}{\partial \lambda}\right)^{2}+4 A a \cdot \frac{\partial A}{\partial \lambda} \cdot\left(d_{1}+\frac{A t}{2}\right)}-a \cdot \frac{\partial A}{\partial \lambda}}{\frac{\partial A}{\partial \lambda} \cdot\left(2 d_{1}+A t\right)}
$$


the optimal advertising input level $m^{*}(t)$ is lower with the increasing of the external intensity; when the market externality is negative i.e. $\lambda<-1$ and $r^{2}<b k$, the optimal advertising input level $m^{*}(t)$ decreases with the decreasing of the external intensity (the absolute value of $\lambda$ decreases).

Proof: Because $m^{*}(t)=\frac{A r}{2 b k} \cdot\left(d_{1}+\frac{a}{\lambda}\right) \cdot \mathrm{e}^{\frac{A t}{2}}$, so

$$
\frac{\partial m^{*}(t)}{\partial \lambda}=\frac{r}{2 b k} \cdot\left[\frac{\partial A}{\partial \lambda} \cdot\left(d_{1}+\frac{a}{\lambda}\right)+\frac{\partial A}{\partial \lambda} \cdot \frac{A t}{2}-\frac{A a}{\lambda^{2}}\right] \cdot \mathrm{e}^{\frac{A}{2} t} .
$$

Because $\partial A / \partial \lambda=(-2 f) / \sqrt{1-4 \lambda f}$ and with the previous assumptions about $\lambda$ and $f$, so when $\lambda>0$ and $\frac{\partial A}{\partial \lambda}>0$, there is $\lambda<-1$ and $\frac{\partial A}{\partial \lambda}<0$. Through analyzing of Formula (18), when $\lambda>0$ and $r^{2}>2 b k$ is established, there is $\frac{\partial A}{\partial \lambda}>0$. If the external strength meets

$$
\lambda>\left(\sqrt{\left(a \cdot \frac{\partial A}{\partial \lambda}\right)^{2}+4 A a \cdot \frac{\partial A}{\partial \lambda} \cdot\left(d_{1}+\frac{A t}{2}\right)}-a\right) / \frac{\partial A}{\partial \lambda} \cdot\left(2 d_{1}+A t\right)
$$

so there is $\partial m^{*}(t) / \partial \lambda<0$; otherwise, $\partial m^{*}(t) / \partial \lambda \geq 0$. Analyzing the Formula (18), when $\lambda<-1$ and $\frac{\partial A}{\partial \lambda}<0$ are established, $\partial m^{*}(t) / \partial \lambda<0$ is founded apparently. Proposition 3 is proved.

Proposition 3 shows that the products with the positive market externality can reduce the manufacturer's advertising investment. Meanwhile manufacturers can improve the product quality and service level to reduce the negative market externality of the product, and so the sales and profit will increase along with the advertising investment decreasing.

Proposition 4: Regardless of whether the market externality of the sold products is positive or negative, the ratio of the optimal advertising input level to the optimal price decreases with the increasing of the external intensity (the absolute value of $\lambda$ becomes larger).

Proof: according to the optimal price $p^{*}(t)$ and the optimal advertising input level $m^{*}(t)$, it can be calculated

$$
\frac{m^{*}(t)}{p^{*}(t)}=\frac{A b r}{(A-2 \lambda f) r^{2}-(A-4 \lambda f) b k} .
$$

By calculating Formula (19) on the intensity of the first derivative, that will be got

$$
\frac{\partial\left(\frac{m^{*}(t)}{p^{*}(t)}\right)}{\partial \lambda}=\frac{-2 b^{2} A r k \cdot\left(1-\lambda \cdot \frac{\partial A}{\partial \lambda}\right)}{\left((A-2 \lambda f) r^{2}-(A-4 \lambda f) b k\right)^{2}} .
$$

Though analyzing, It is can be deduced that $1-\lambda \cdot \frac{\partial A}{\partial \lambda}=1+\frac{2 \lambda f}{A-1}>0$ no matter how the parameter $\lambda$ meets $\lambda>0$ or $\lambda<-1$. Obviously it is estab- 
lished that $\partial\left(\frac{m^{*}(t)}{p^{*}(t)}\right) / \partial \lambda<0$ because of $2 b^{2} A r k>0$. Proposition 4 is proved.

Proposition 5: when the products' externality is positive, the impact of positive market externality on the product sales is different, and it is related to the sale time. If the product sales time meets $t \geq-\frac{2}{A}-\frac{a(A-1)}{\lambda f \cdot\left(a+d_{1} \lambda\right)}$, the product sales at $t$ time will increase with the more stronger market externality, otherwise the sales will reduce. The time $t^{*}=-\frac{2}{A}-\frac{a(A-1)}{\lambda f \cdot\left(a+d_{1} \lambda\right)}$ is the critical point of the positive market externality which has different influence on sales.

Proof: if $\lambda>0$ and $D(t)=-\frac{a}{\lambda}+\left(d_{1}+\frac{a}{\lambda}\right) \cdot \mathrm{e}^{\frac{A}{2} t}$, so $D^{\prime}(t)=\frac{A}{2} \cdot\left(d_{1}+\frac{a}{\lambda}\right) \cdot \mathrm{e}^{\frac{A}{2} t}$. Calculating the derivative of the $D^{\prime}(t)$ on coefficient $\lambda$, we can get:

$$
\frac{\partial D^{\prime}(t)}{\partial \lambda}=\frac{1}{2} \mathrm{e}^{\frac{A}{2} t} \cdot\left[\frac{\partial A}{\partial \lambda} \cdot\left(d_{1}+\frac{a}{\lambda}\right) \cdot\left(1+\frac{1}{2} t A\right)-\frac{A a}{\lambda^{2}}\right] .
$$

According to the previous calculation, there is: $A=\sqrt{1-4 \lambda f}+1>0$, $f=\frac{b k}{2 b k-r^{2}}, \frac{\partial A}{\partial \lambda}=\frac{-2 f}{\sqrt{1-4 \lambda f}}$, so when $\lambda>0, \frac{\partial A}{\partial \lambda}>0$ is established. If $t \leq-\frac{2}{A}-\frac{a(A-1)}{\lambda f \cdot\left(a+d_{1} \lambda\right)}$, it can be got that $\frac{\partial D^{\prime}(t)}{\partial \lambda} \leq 0$; instead $\frac{\partial D^{\prime}(t)}{\partial \lambda}>0$ is established when $t>-\frac{2}{A}-\frac{a(A-1)}{\lambda f \cdot\left(a+d_{1} \lambda\right)}$. This shows that the instant sales are the lowest at $t$ time $\left(t=-\frac{2}{A}-\frac{a(A-1)}{\lambda f \cdot\left(a+d_{1} \lambda\right)}\right)$. Proposition 5 is proved.

Proposition 6: If products' market externality is negative (i.e. $\lambda<-1$ ), the sales of product at $t$ time continue to decreases as negative market externality gets weakened (the absolute value of $\lambda$ decreases).

Proof: it is established that $\frac{\partial D^{\prime}(t)}{\partial \lambda}=\frac{1}{2} \mathrm{e}^{\frac{A}{2} t} \cdot\left[\frac{\partial A}{\partial \lambda} \cdot\left(d_{1}+\frac{a}{\lambda}\right) \cdot\left(1+\frac{1}{2} t A\right)-\frac{A a}{\lambda^{2}}\right]$ according to the previous analysis. Further analysis shows that there is $\frac{\partial A}{\partial \lambda}=\frac{-2 f}{A-1}<0$ if $\lambda<-1$. So $\frac{\partial D^{\prime}(t)}{\partial \lambda}<0$ is established when $\left[\frac{\partial A}{\partial \lambda} \cdot\left(d_{1}+\frac{a}{\lambda}\right) \cdot\left(1+\frac{1}{2} t A\right)-\frac{A a}{\lambda^{2}}\right]<0$. Therefore, in the case of $\lambda$ is negative, the product's instant sales with the increasing of $\lambda$ ( $\lambda$ absolute value is small) continue to reduce. Prove is finished.

\section{Conclusions and Prospect}

The manufacturer could use advertising to accelerate product diffusion and increase product sales in the early stage of the product entering the market. When consumers buy and use the products, products will have externality in the mar- 
ket that affects product diffusion and firm decision. So it is much valuable to study the effect of externality on dynamic decision making for monopoly. The dynamic model is built including price, advertising level and externality in this paper, using the control theory to calculate the optimal price, advertising level control strategy and the actual product total demand, and also analyzes the change trend of relevant parameters in different conditions. The main conclusions are: when the product has different market externalities, the optimal advertising investment level and the optimal price have different trends with the increasing of external strength; especially, whether the product has positive market externality or negative market externality, the ratio of the optimal advertising investment level to the optimal price decreases with the increasing of external strength. Under different conditions, the effect of market externality on product sales is different. Research on the influence of product monopoly externality on dynamic decision can provide a theoretical basis for monopoly that makes dynamic decision and control in different sales periods. The monopoly should make full use of the products' positive externality to save costs and increase revenue.

This paper discusses the influence of product externality on monopoly firm's dynamic decision, but competitive market structure of multiple firms is more common in practice. External influences on firms' dynamic decision are not the same for different categories of products, external influence, and it is the limitations of the study. In the future, we will examine the externalities of different types of products such as durable goods and perishable goods, or research the impact of externality on product diffusion processes under different factors such as word of mouth and so on.

\section{References}

[1] Bass, F.M. (1969) A New Product Growth Model for Consumer Durable Goods. Management Science, 13, 215-227. https://doi.org/10.1287/mnsc.15.5.215

[2] Kalis, S. and Sen, S.K. (1986) Diffusion Models and the Marketing Mix for Single Products. In: Mahajan, V. and Wind, Y., Eds., Innovation Diffusion Models of New Product Acceptance, MA. Ballinger Publishing Company, Cambridge, 20-30.

[3] Jain, D. and Rao, R.C. (1990) Effect of Price on Demand for Durable: Modeling, Estimation and Findings. Journal of Business and Economic Statistics, 8, 163-170.

[4] Xie, J.H. and Marvin, S. (1995) Price Competition and Compatibility in the Presence of Positive Demand Externality. Management Science, 41, 909-926. https://doi.org/10.1287/mnsc.41.5.909

[5] Richard, S. (1994) Quality Regulation of Durable Goods in the Presence of Externality. Stanford University, California.

[6] Austan, G. and Edward, M.L. (2000) Coveting the Neighbor's Manufacturing: The Dilemma of State Income Apportionment. Journal of Public Economics, 75, 125-143. https://doi.org/10.1016/S0047-2727(99)00036-5

[7] Didier, L., Montmarin, M.D. and Van, L.N. (2004) Dynamic Duopoly with Congestion Effects. International Journal of Industrial Organization, 22, 655-677. https://doi.org/10.1016/j.ijindorg.2004.02.001

[8] Jonah, B., Alan, T.S. and Scott, J.R. (2010) Positive Effects of Negative Publicity: 
When Negative Reviews Increase Sales. Marketing Science, 29, 815-827. https://doi.org/10.1287/mksc.1090.0557

[9] Pan, X.J., Chen, H.M. and Hou, H.Y. (2006) Monopoly Pricing Strategy with Network Externality. Journal of Industrial Engineering/Engineering Management, 20, 67-71.

[10] Manchanda, P., Xie, Y. and Youn, N. (2008) The Role of Targeted Communication and Contagion in Product Adoption. Marketing Science, 27, 961-976. https://doi.org/10.1287/mksc.1070.0354

[11] Bing, J. (2011) Social Learning and Dynamic Pricing of Durable Goods. Marketing Science, 6, 1-14.

[12] Nielsen (2009) Global Advertising Consumers Trust Real Friends and Virtual Strangers the Most. Newswire (Blog), July 7.

http://www.nielsen.com/us/en/newswire/2009/global-advertising-consumers-trust-r eal-friends-and-virtual-strangers-the-most.html

[13] Nielsen (2012) How Connectivity Influences Global Shopping. Newswire (Blog), August 28.

http://www.nielsen.com/us/en/newswire/2012/how-connectivity-influences-global-s hopping.html

[14] Gopinath, S., Thomas, J. and Krishmamurthi, L. (2014) Investigating the Relationship between Online Word of Mouth, Advertising and Brand Performance. Marketing Science, 33, 241-258. https://doi.org/10.1287/mksc.2013.0820

[15] Godes, D. (2016) Product Policy in Markets with Word-of-Mouth Communication. Management Science, 5, 267-278.

[16] Fossen, B.L. and Schweidel, D.A. (2017) Television Advertising and Online Wordof-Mouth: An Empirical Investigation of Social TV Activity. Marketing Science, 36, 105-123. https://doi.org/10.1287/mksc.2016.1002

[17] Zhang, J.J., Zhao, J. and Zhang, Y.X.(2006) Supply Chain Reputation and Its Differential Game Based on Dynamic Game in Continuous Time. Journal of Industrial Engineering/Engineering Management, 26, 145-150.

[18] Yi, Y.-Y. (2013) Coordination Performance of Closed-Loop Supply Chain with Advertising Effect. Chinese Journal of Management Science, 21, 76-83.

[19] Huang, Z.-S., Nie, J.-J. and Hu, P. (2013)Dynamic Closed-Loop Supply Chain Models with Product Remanufacturing. Journal of Industrial Engineering /Engineering Management, 27, 93-102.

[20] Dan, B., Tian. L.-N. and Dong, S.-H. (2013) Research on Advertising DecisionMarking Model between Complementary Goods Enterprise Considering Spillover Effect. Chinese Management Science, 21, 66-74. 
Submit or recommend next manuscript to SCIRP and we will provide best service for you:

Accepting pre-submission inquiries through Email, Facebook, LinkedIn, Twitter, etc. A wide selection of journals (inclusive of 9 subjects, more than 200 journals)

Providing 24-hour high-quality service

User-friendly online submission system

Fair and swift peer-review system

Efficient typesetting and proofreading procedure

Display of the result of downloads and visits, as well as the number of cited articles Maximum dissemination of your research work

Submit your manuscript at: http://papersubmission.scirp.org/

Or contact me@scirp.org 